\title{
Design and Evaluation of Tapped Inductors for High-Voltage Auxiliary Power Supplies for Modular Multilevel Converters
}

\author{
Tomas Modeer*, Mariusz Zdanowski ${ }^{\dagger}$ and Hans-Peter Nee ${ }^{\ddagger}$ \\ *Dept. of Electrical Energy Conversion, KTH Royal Institute of Technology, Stockholm, Sweden, Email: tm@kth.se \\ ${ }^{\dagger}$ Inst. of Control and Industrial Electronics, Warsaw University of Technology, \\ Warsaw, Poland, Email: mariusz.zdanowski@ee.pw.edu.pl \\ ${ }_{\ddagger}^{\ddagger}$ Dept. of Electrical Energy Conversion, KTH Royal Institute of Technology, Stockholm, Sweden, Email: hansi@kth.se
}

\begin{abstract}
Tapped-inductor buck converters can provide large step-down ratios at high efficiency and are well suited in auxiliary power supplies for modular multilevel converter cells supplying gate drive units etc. In this paper the design and testing of three low-leakage tapped inductors for use in a $3 \mathrm{kV}, 100 \mathrm{~W}$ buck converter is described.
\end{abstract}

Index Terms-tapped inductor, modular multilevel converter, leakage inductance

\section{INTRODUCTION}

The modular multilevel converter (M2C), which was first presented by Marquardt et al [1]-[3], seems to be the ideal converter for several high-power applications such as highvoltage direct current transmission (HVDC) [4]-[8], electric railway supplies [9], [10], and high-power motor drives [11][14]. In all cases the submodules of the converter require an auxiliary power supply for the gate drivers and for local control and measurement systems. From a reliability perspective it is desirable that the auxiliary power is taken from the main circuit [15], [16] because this eliminates the need for a dedicated power source. However, if the auxiliary power should be taken from the main circuit, the input voltage of the auxiliary power supply could be several kilovolts. This means that no standard solutions are available. A comparison of different possible converter topologies reveals that the tapped-inductor buck converter [17], shown in Fig. 1, is a very promising alternative.

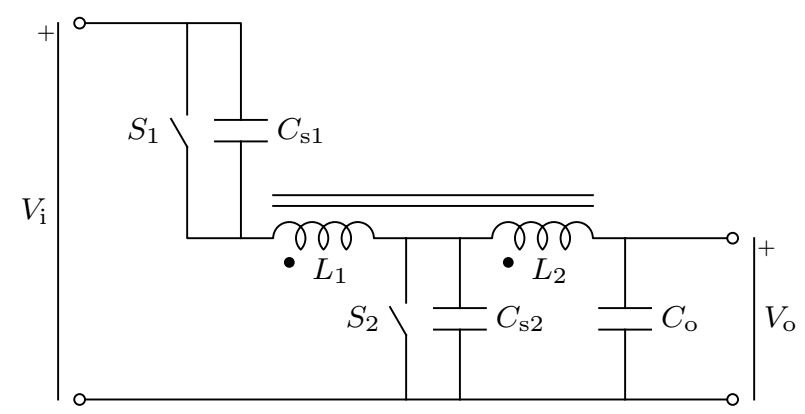

Fig. 1. Tapped-inductor buck converter topology.
TABLE I

CONVERTER SPECIFICATION

$\begin{array}{lll}\text { Input voltage } & V_{\mathrm{i}} & 3 \mathrm{kV} \\ \text { Output voltage } & V_{\mathrm{o}} & 100 \mathrm{~V} \\ \text { Output power } & P & 100 \mathrm{~W} \\ \text { Switching frequency } & f_{\mathrm{s}} & \geq 20 \mathrm{kHz} \\ \text { Conduction mode } & & \text { Discontinuous }\end{array}$

A vital component in this converter is the tapped inductor itself. From circuit simulations and preliminary experiments it was found that the leakage inductance of the tapped inductor should be minimized in order to optimize the efficiency of the converter. As will be shown below, design of such an inductor is not trivial. It is the intention of this paper to describe the design process of such an inductor and to build and evaluate a first series of prototypes. Both the design process and the evaluation focus on the minimization of the leakage inductance, and it is experimentally verified that leakage inductances of the order of 0.8 percent are achievable. The general specifications of a step-down converter suitable for powering a high power M2C submodule are given in Table I.

\section{INDUCTOR DESIGN}

One of the main issues in the design of a tapped-inductor buck converter is the design of the tapped inductor itself. Firstly, the inductor must provide sufficient energy storage and inductance to allow efficient operation and limit the stress of the other converter components. Secondly, the insulation system must be designed to withstand the voltage stress. Furthermore, the leakage inductance of the tapped inductor must be low as to minimize the voltage overshoot at the center tap. The energy stored in the leakage inductance must be absorbed by the stray capacitance of the synchronous rectifier switch and, if necessary, by an additional snubber capacitor so as to limit the voltage. Such an additional snubber capacitor increases the current loading of the switch and inductor and will lower the efficiency. It would thus be beneficial to minimize the leakage inductance as to not have to include a snubber capacitor across the synchronous rectifier switch.

The design of a low leakage tapped inductor, or transformer, is not trivial and many different designs have been proposed. 
Among these are designs based on coaxial winding arrangements [18] and interleaved planar designs [19].

Coaxial winding transformers can provide very high coupling factors [18], but large turns ratio are not easily accomodated. Planar transformers allow for good manufacturability also with extensive interleaving which is the main reason for the low leakage possible of planar transformers [20]. The electrical insulation of planar transformers is however not trivial, and although a $15 \mathrm{kV}$ design has been presented [19] the insulation is complex and takes up a prohibitively large part in low power transformers. For realiability, size and cost reasons it would be beneficial to manufacture the tapped inductor using conventional solenoidal inductive component manufacturing methods.

The leakage inductance of the tapped inductor is due to the spatial displacement of the high and low voltage windings, as discussed in e.g. [21]. Most of the displacement is due to the necessary electrical isolation. Polyimide film can provide excellent electrical isolation and can withstand short duration electrical stress exceeding $30 \mathrm{kV} / \mathrm{mm}$ without breakdown [23]. However, to ensure a long lifetime the stress must be limited to approximately $2.5-3.0 \mathrm{kV} / \mathrm{mm}$ to reach the treshold where negligible aging occurs [23], [24].

The leakage inductance referred to a winding can be expressed as

$$
L_{1}=\frac{N^{2}}{\mathfrak{R}_{1}}
$$

where $N$ is the number of turns in the winding and $\mathfrak{R}_{1}$ can be considered the reluctance of the leakage path. For a transformer or tapped inductor with single-layer solenoidal windings of equal length the leakage can be approximated by the reluctance of a cylindrical shell with a length equal to the winding axial length and with a thickness equal to the difference between the winding radii. The radial spacing is mainly given by electrical insulation requirements and can thus be considered constant with respect to core choice. This implies that the leakage reluctance is not dependent on core size, only on core shape [20].

The minimum magnetizing reluctance is on the other hand heavily dependent on core size. Considering a core with a single air-gap, the energy stored in the airgap is

$$
E=\frac{1}{2} \int_{V} B H \mathrm{~d} V=\frac{1}{2} \frac{1}{\mu_{0} \mu_{\mathrm{r}}} \hat{B}^{2} \delta A
$$

where $\hat{B}$ is the permissible maximum flux density, $\delta$ is the airgap length and $A$ is the airgap cross-section. For a given energy storage requirement $E$ the minimum required gap separation $\delta$ is

$$
\delta=2 \cdot \frac{\mu_{0} \mu_{\mathrm{r}} E}{\hat{B}^{2} A}
$$

and the reluctance of the airgap is

$$
\mathfrak{R}_{\mathrm{ag}}=\frac{\delta}{\mu_{0} \mu_{\mathrm{r}} A}=\frac{2 E}{\hat{B}^{2} A^{2}} .
$$

The magnetizing reluctance under these assumption thus scales to the inverse of square of the magnetic cross-section of the core, or to the inverse of the length scale to the power of four. Thus, to minimize the normalized leakage inductance a relatively large core should be used. For the converter under consideration the energy storage requirement is approximately

$$
E=\frac{P_{\mathrm{o}}}{2 \cdot f_{\mathrm{s}}} \approx 2.5 \mathrm{~mJ}
$$

Choosing a suitable ferrite core using e.g. the area product method [22] with peak flux density $\hat{B}=0.3 \mathrm{~T}$, current density $J=2 \mathrm{~A} / \mathrm{mm}^{2}$ and winding fill factor $K_{\mathrm{u}}=0.5$ the required area product is

$$
A_{\mathrm{p}}=\frac{2 W}{K_{\mathrm{u}} J_{\mathrm{M}} B_{\mathrm{M}}} \approx 1.7 \cdot 10^{-8} \mathrm{~m}^{4}
$$

which could be accomodated by e.g. an ETD39 core $\left(A_{\mathrm{p}}=\right.$ $\left.2.2 \cdot 10^{-8} \mathrm{~m}^{4}\right)$. By choosing a larger ETD59 core $\left(A_{\mathrm{p}}=\right.$ $\left.1.35 \cdot 10^{-7} \mathrm{~m}^{4}\right)$ the leakage inductance can be reduced and as a much lower fill factor can be accepted both windings can be accomodated in just a few layers.

\section{INDUCTOR PROTOTYPES}

A first prototype was made with the high and low voltage windings distributed in two layers as shown in Fig. 2. It was
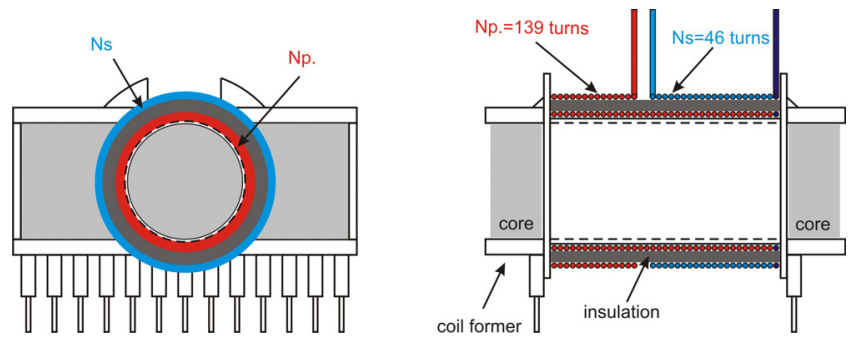

Fig. 2. Tapped inductor winding layout, first prototype. High-voltage winding $(\mathrm{Np})$ in red and low-voltage winding (Ns) in blue

anticipated that the leakage inductance would be low as the radial displacement of the windings was small. It turned out that the leakage inductance, as shown in Table II Prototype No 1 , was quite large due to the axial displacement of the windings.

A second prototype was made with high and low voltage windings of equal axial length. Also, a first order interleaving [20] was utilized to minimize the leakage inductance. The winding arrangement of the second prototype is shown in Fig. 3 and a photograph is shown in Fig. 4. The insulation between the layers is made from three layers of $65 \mu \mathrm{m}$ polyimide film tape which can withstand the electric field stress and has excellent resistance to partial discharge degradation. The film tape extends approximately $4 \mathrm{~mm}$ on each side of the winding layers to provide sufficient creepage distance.

The turns ratio of the second prototype was fixed to $2: 1$ due to the use of equal wire diameters $(\varnothing 0.4 \mathrm{~mm})$ and equal winding width of all winding layers. This turns ratio is too low for a tapped inductor buck converter with a large stepdown ratio [17] and a third prototype with a larger turns ratio was made. This was accomplished by winding the low voltage 
TABLE II

PROTOTYPE MEASURED INDUCTANCE

\begin{tabular}{llll} 
Prototype & 1 & 2 & 3 \\
\hline Winding layers & 2 & 3 & 3 \\
$N_{p}$ & 139 turns & 124 turns & 140 turns \\
$N_{s}$ & 46 turns & 62 turns & 17 turns \\
$L_{t o t}$ & $12.8 \mathrm{mH}$ & $12.8 \mathrm{mH}$ & $11.4 \mathrm{mH}$ \\
$L_{1}$ & $7.31 \mathrm{mH}$ & $5.64 \mathrm{mH}$ & $9.09 \mathrm{mH}$ \\
$L_{2}$ & $865 \mu \mathrm{H}$ & $1.46 \mathrm{mH}$ & $133 \mu \mathrm{H}$ \\
$L_{L}$ & $15.7 \%$ & $0.3 \%$ & $0.8 \%$
\end{tabular}

winding with a two parallel strands of thicker wire $(\varnothing 0.8 \mathrm{~mm})$ so that the width of the low-voltage winding matches that of the high-voltage windings.

\section{INDUCTOR CHARACTERISATION AND TESTING}

The inductor magnetizing inductances and leakage inductances were measured at $10 \mathrm{kHz}$ and $1 \mathrm{~V}$ using a WK TMPO 4230 LCR-meter. The leakage inductance was measured by short circuiting one part of the winding and measuring the inductance of the other part. The measured inductances of the three prototypes are given in Table II.
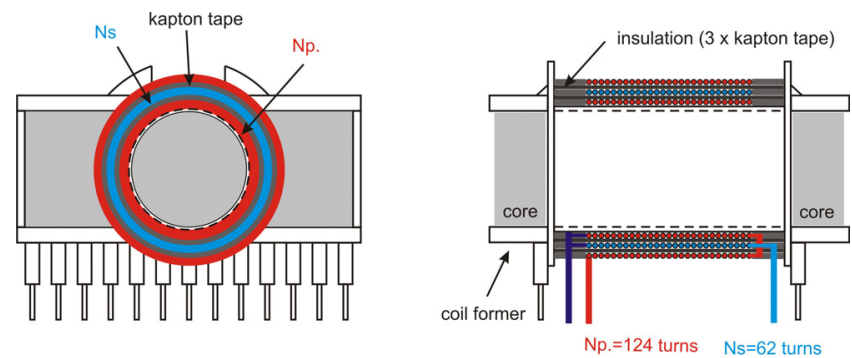

Fig. 3. Tapped inductor winding layout, second prototype. High-voltage winding $(\mathrm{Np})$ in red and low-voltage winding $(\mathrm{Ns})$ in blue

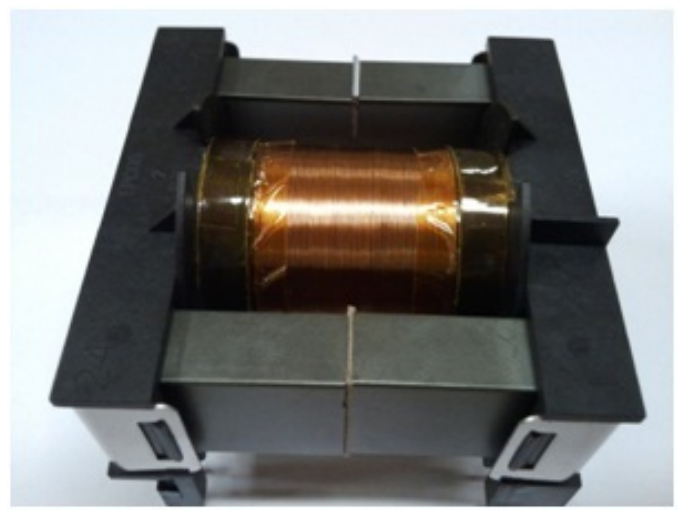

Fig. 4. Tapped inductor, second prototype.

The intented application for the inductor is tapped-inductor buck converters with current injection [17] which allows softswitching of the main switch. The current injection is achieved by allowing the current in the synchronous rectifier reverse and reach a negative value before turning off. At turn-off of the synchronous rectifier the energy stored in the inductor will charge the stray and snubber capacitors of the main switch and, if sufficient energy is stored, drive the voltage over the main switch to zero, which allows a soft turn on. In cases with non-negligible leakage inductance the voltage over the synchronous rectifier can reach destructive levels. The energy stored in the leakage inductance must thus be absorbed by the synchronous switch stray and snubber capacitance to clamp the voltage.

The inductors were tested in a boost-configuration circuit to evaluate the effect of the leakage inductance. For the switching test it is not necessary to use a high voltage supply, instead only an appropriately sized $(150 \mathrm{pF})$ snubber capacitor was connected between the inductor high voltage lead and the negative supply rail as shown in Fig. 5. The low-voltage side

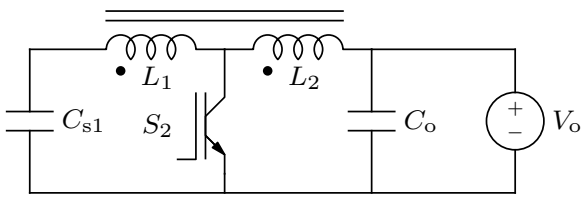

Fig. 5. Tapped inductor test circuit.

was supplied by a low-voltage supply (30 V) and a $1200 \mathrm{~V}$ IGBT (Infineon SK30GAL123) was used as synchronous rectifier switch. For the switching test the synchronous rectifier switch is turned on and current is allow to reach such a level that when the switch is turned off the voltage over the snubber capacitor $C_{\mathrm{S} 1}$ reaches more than $3 \mathrm{kV}$, which would allow soft turn-on of the main switch in the actual converter. The waveforms for the first prototype are shown in Fig. 6. The large leakage inductance of prototype 1 causes significant ringing between the leakage inductance and the main switch snubber capacitor. The leakage inductance referred to the high-voltage winding is approximately $1.15 \mathrm{mH}$, the main switch snubber capacitance, $C_{\mathrm{S} 1}$ is $150 \mathrm{pF}$, and the corresponding ringing frequency is approximately $380 \mathrm{kHz}$. The second prototype has much lower leakage inductance and no ringing is discernible in Fig. 7. The center-tap voltage of prototype 2 is too high due to the low turns ratio, allowing no margin for high output voltages. The turns ratio of prototype 3 is much larger and as shown in Fig. 8 the center-tap voltage reaches only $330 \mathrm{~V}$. This means that the synchronous rectifier can be a $800 \mathrm{~V}$ super-junction MOSFET and there is still margin for an output voltage around $300 \mathrm{~V}$.

\section{CONCLUSION}

It has been shown that a tapped inductor for use in a $3 \mathrm{kV}$ tapped-inductor buck converter can be made using commonplace solenoidal inductor manufacturing methods and still provide a sufficiently low leakage inductance $(\leq 1 \%)$ to ensure high-effiency operation. If cost and size restrictions allow, a large core should be used in order to minimize the leakage inductance, in other cases extensive interleaving must be used to obtain low leakage. 


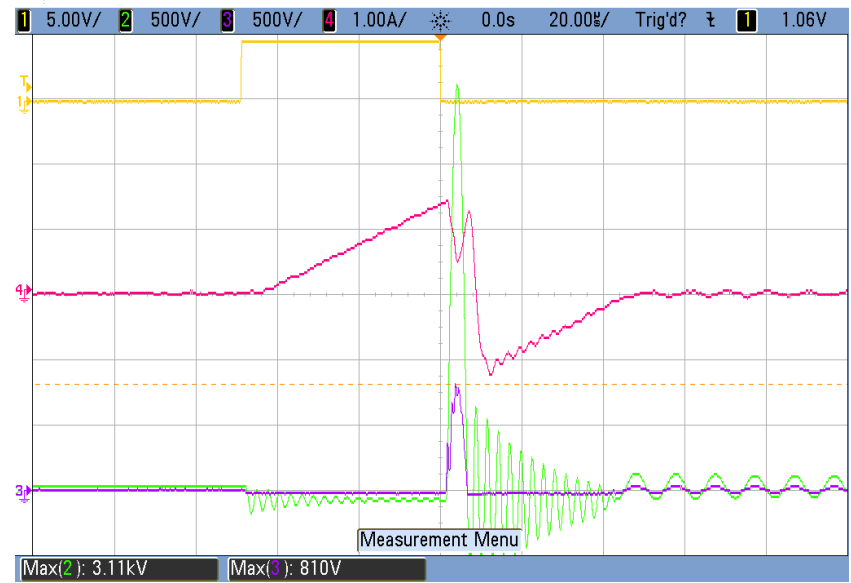

Fig. 6. Tapped inductor switching test, prototype 1. Channel 1 (Yellow) is the gate signal for the synchronous rectifier switch, Channel 2 (Green) and 3 (Purple) is the voltages at the tapped inductor high-voltage connection and center tap respectively. Channel 4 (Magenta) is the current through the low voltage winding. Due to the large leakage inductance of prototype 1 the waveforms show significant ringing between the leakage inductance and the main swith snubber capacitor $\left(C_{\mathrm{S} 1}\right)$
Agilent Technologies

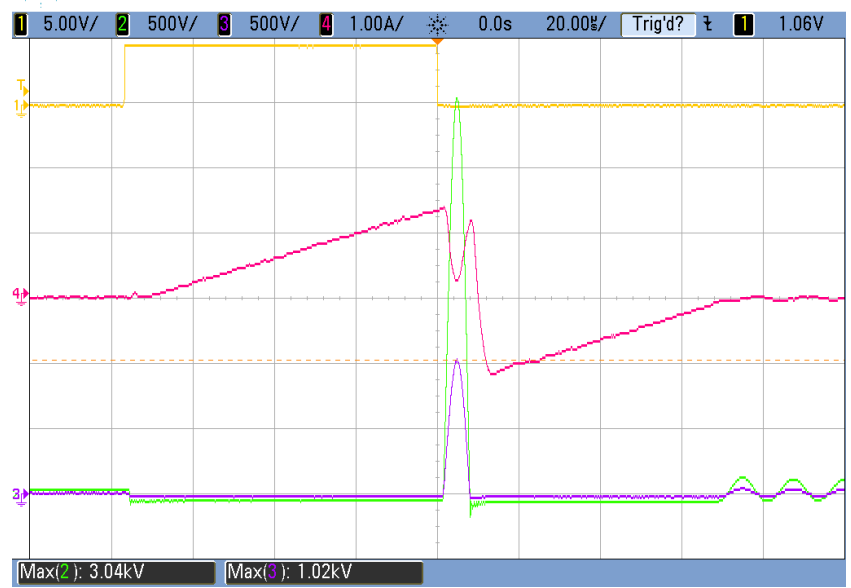

Fig. 7. Tapped inductor switching test, prototype 2. Channel setup as described in Fig. 6. No discernable ringing due to the low leakage inductance $(0.3 \%)$

\section{REFERENCES}

[1] A. Lesnicar and R. Marquardt, "An innovative modular multilevel converter topology suitable for a wide power range," in Proc. IEEE Bologna Power Tech, vol. 3, 2003.

[2] A. Lesnicar and R. Marquardt, "A new modular voltage source inverter topology," in Proceedings of the 10th European Conference on Power Electronics and Applications, EPE 03, 2003.

[3] M. Glinka and R. Marquardt, "A new ac/ac multilevel converter family," IEEE Transactions on Industrial Electronics, vol. 52, pp. 662-669, jun 2005.

[4] S. Allebrod, R. Hamerski, and R. Marquardt, "New transformerless, scalable modular multilevel converters for HVDC-transmission," in Proc. IEEE Power Electronics Specialists Conf. PESC 2008, pp. 174 179, 2008.

[5] R. Marquardt, "Modular multilevel converter: An universal concept for

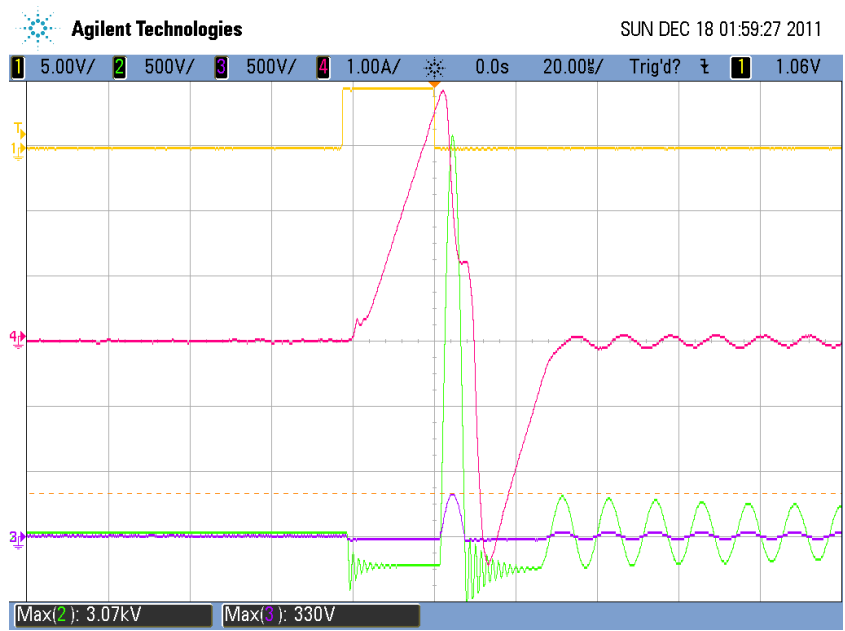

Fig. 8. Tapped inductor switching test, prototype 3. Channel setup as described in Fig. 6. The low secondary inductance requires more current $(\approx 4 \mathrm{~A})$ to store the necessary energy to ensure soft switching.

HVDC-networks and extended DC-bus-applications," in Proc. Int. Power Electronics Conf. (IPEC), pp. 502-507, 2010.

[6] T. Modeer, H.-P. Nee, and S. Norrga, "Loss comparison of different submodule implementations for modular multilevel converters in HVDC applications," in Proc. 2011-14th European Conf. Power Electronics and Applications (EPE 2011), pp. 1-7, 2011.

[7] N. Ahmed, A. Haider, D. Van Hertem, L. Zhang, and H.-P. Nee, "Prospects and challenges of future HVDC supergrids with modular multilevel converters," in Proc. 2011-14th European Conf. Power Electronics and Applications (EPE 2011), pp. 1-10, 2011.

[8] D. Peftitsis, G. Tolstoy, A. Antonopoulos, J. Rabkowski, J. Lim, M. Bakowski, L. Ängquist, and H. Nee, "High-power modular multilevel converters with SiC JFETs," Power Electronics, IEEE Transactions on, vol. 27, pp. 28-36, jan 2012

[9] M. Winkelnkemper, A. Korn, and P. Steimer, "A modular direct converter for transformerless rail interties," in Proc. IEEE Int Industrial Electronics (ISIE) Symp, pp. 562-567, 2010.

[10] L. Angquist, A. Haider, H.-P. Nee, and H. Jiang, "Open-loop approach to control a modular multilevel frequency converter," in Proc. 201114th European Conf. Power Electronics and Applications (EPE 2011), pp. 1-10, 2011.

[11] M. Hiller, D. Krug, R. Sommer, and S. Rohner "A new highly modula medium voltage converter topology for industrial drive applications," in Proc. 13th European Conf. Power Electronics and Applications EPE '09, pp. 1-10, 2009.

[12] A. Antonopoulos, K. Ilves, L. Angquist, and H.-P. Nee, “On interaction between internal converter dynamics and current control of high-performance high-power ac motor drives with modular multilevel converters," in Proc. IEEE Energy Conversion Congress and Exposition (ECCE), pp. 4293-4298, 2010.

[13] M. Hagiwara, K. Nishimura, and H. Akagi, "A medium-voltage motor drive with a modular multilevel pwm inverter," IEEE Transactions on Power Electronics, vol. 25, no. 7, pp. 1786-1799, 2010.

[14] A. J. Korn, M. Winkelnkemper, and P. Steimer, "Low output frequency operation of the modular multi-level converter," in Proc. IEEE Energy Conversion Congress and Exposition (ECCE), pp. 3993-3997, 2010.

[15] J. Holtz and R. Rosner, "Gate drive power recovery and regenerative snubber scheme for series-connected GTOs in high voltage inverters," in Proc. Thirty-Fourth IAS Annual Meeting Industry Applications Conf. Conf. Record of the 1999 IEEE, vol. 3, pp. 1535-1540, 1999.

[16] T. Kjellqvist, S. Ostlund, and S. Norrga, "Active snubber circuit for source commutated converters utilizing the IGBT in the linear region," IEEE Transactions on Power Electronics, vol. 23, no. 5, pp. 2595-2601, 2008.

[17] J.-H. Park and B.-H. Cho, "Nonisolation soft-switching buck converter with tapped-inductor for wide-input extreme step-down applications," 
IEEE Transactions on Circuits and Systems I: Regular Papers, vol. 54, no. 8, pp. 1809-1818, 2007.

[18] P.-T. Cheng, S.-Y. Yang, Y. Guan, and S.-S. Wang, "Design and implementation of oaxial winding transformers for isolated dc-dc converters," in Proc. Power Conversion Conf. - Nagoya PCC '07, pp. 9-15, 2007.

[19] Y. A. Wang, D. M. Xiao, and Y. L. Liu, "Design of a planar power transformer for high voltage, high frequency use," in Proc. IEEE PES Transmission and Distribution Conf. and Exposition, pp. 1-6, 2010.

[20] B. W. Carsten, "The low leakage inductance of planar transformers; fact or myth?," in Proc. Sixteenth Annual IEEE Applied Power Electronics Conf. and Exposition APEC 2001, vol. 2, pp. 1184-1188, 2001.

[21] P. L. Dowell, "Effects of eddy currents in transformer windings," Proceedings of the Institution of Electrical Engineers, vol. 113, no. 8, pp. 1387-1394, 1966.

[22] C. McLyman, Transformer and inductor design handbook, vol. 121. CRC press, 2004.

[23] H. Hirose, "A method to estimate the lifetime of solid electrical insulation," Electrical Insulation, IEEE Transactions on, vol. EI-22, pp. $745-753$, dec. 1987.

[24] Q. Zhuang, P. H. F. Morshuis, X. C. Chen, J. J. Smit, and Z. X. Xu, "Life prediction of a full-scale transformer winding insulation through statistical analysis of ac voltage endurance test data," vol. 19, no. 2, pp. 460-471, 2012 